\title{
Circadian CLOCK Mediates Activation of Transforming Growth Factor- $\beta$ Signaling and Renal Fibrosis through Cyclooxygenase 2
}

Wei-Dar Chen, ${ }^{*}$ Jih-Kai Yeh, ${ }^{*}$ Meng-Ting Peng, ${ }^{\dagger}$ Shian-Sen Shie, ${ }^{\ddagger}$ Shuei-Liong Lin, ${ }^{\S}$ Chia-Hung Yang, ${ }^{*}$ Tien-Hsing Chen, ${ }^{*}$ Kuo-Chun Hung, ${ }^{*}$ Chun-Chieh Wang, ${ }^{*}$ I-Chang Hsieh, ${ }^{*}$ Ming-Shien Wen, ${ }^{*}$ and Chao-Yung Wang ${ }^{*}$

From the Departments of Cardiology, ${ }^{*}$ Oncology, ${ }^{\dagger}$ and Infectious Disease ${ }^{\ddagger}$ Chang Gung Memorial Hospital, Chang Gung University College of Medicine, Taoyuan; the Renal Division, ${ }^{\S}$ Department of Medicine, National Taiwan University Hospital, Taipei; and Graduate Institute of Physiology, ${ }^{\circledR}$ National Taiwan University, College of Medicine, Taipei, Taiwan

Accepted for publication August 11, 2015.

Address correspondence to Chao-Yung Wang, M.D., Chang Gung Memorial Hospital, Chang Gung University College of Medicine, 5 Fu-Hsing St., Taoyuan 333, Taiwan. E-mail: cwang@ ocean.ag.

\begin{abstract}
The circadian rhythm regulates blood pressure and maintains fluid and electrolyte homeostasis with central and peripheral clock. However, the role of circadian rhythm in the pathogenesis of tubulointerstitial fibrosis remains unclear. Here, we found that the amplitudes of circadian rhythm oscillation in kidneys significantly increased after unilateral ureteral obstruction. In mice that are deficient in the circadian gene Clock, renal fibrosis and renal parenchymal damage were significantly worse after ureteral obstruction. CLOCK-deficient mice showed increased synthesis of collagen, increased oxidative stress, and greater transforming growth factor- $\beta$ (TGF- $\beta$ ) expression. TGF- $\beta$ mRNA expression oscillated with the circadian rhythms under the control of CLOCK-BMAL1 heterodimers. The expression of cyclooxygenase 2 was significantly higher in kidneys from CLOCK-deficient mice with ureteral obstruction. Treatment with a cyclooxygenase 2 inhibitor celecoxib significantly improved renal fibrosis in CLOCK-deficient mice. Taken together, these data establish the importance of the circadian rhythm in tubulointerstitial fibrosis and suggest CLOCK/TGF- $\beta$ signaling as a novel therapeutic target of cyclooxygenase inhibition. (Am J Pathol 2015, 185: 3152-3163; http://dx.doi.org/10.1016/j.ajpath.2015.08.003)
\end{abstract}

Most physiological and homeostatic processes, including sleep, heart rhythms, arterial blood pressure, and renal blood flow, have intrinsic circadian rhythms. ${ }^{1}$ The circadian rhythm is organized hierarchically and adjusted continuously by environmental clues. ${ }^{2}$ It allows cells and tissues to adapt to metabolic and functional demands as well as diurnal environmental changes. ${ }^{3}$ In mammals, the central circadian pacemaker is located in the suprachiasmatic nucleus of the hypothalamus and is synchronized to the light and dark cycle through the retinohypothalamic tract. ${ }^{4}$ In addition, evidence of peripheral clocks is growing. Peripheral clocks in individual cells or organs have autonomous and self-sustained intrinsic rhythms with tissue-specific functions. ${ }^{5}$ These peripheral clocks are synchronized with the central clock through neuronal and humoral signaling. The molecular components of the circadian system are autoregulated by transcriptional, translational, and posttranslational mechanisms. ${ }^{6}$ One of the important circadian transcription-translation feedback loops operates as the transcription heterodimers BMAL1 and CLOCK bind to the clock gene promoters and increase the expression of the period 1/2 (PER1/2) and cryptochrome 1/2 (CRY 1/2) genes. ${ }^{7}$ PER $1 / 2$ and CRY $1 / 2$ then translocate back to the nucleus to repress their own transcription by inhibiting the CLOCK-BMAL11 complex.

In humans, a dysregulated circadian rhythm increases the incidence of several diseases. Hypertensive patients with disturbed daily blood pressure rhythms show a higher

Supported by NHRI grant NHRI-EX100-9925SC (C.-Y.W.); National Science Council grants 101-2314-B-182-100-MY3 and 101-2314-B-182A009 (C.-Y.W.), and 103-2314-B-182A-092-MY3 (M.-S.W.); and Chang Gung Memorial Hospital grants CMRPG3B1643, CMRPG3D1002, CMRPG3D0581, and CMRPG3C1762 (C.-Y.W.), CMRPG3C1392 (M.-S.W.), and CMRPG3C0722 (S.-S.S.).

W.-D.C. and J.-K.Y. contributed equally to this work.

Disclosures: None declared. 
incidence of vascular disease than other patients. ${ }^{9}$ Shift workers have a $40 \%$ higher risk of cardiovascular disease than the rest of the population. Every 5 years of night-shift work increases the risk of ischemic stroke by $4 \%$ and of breast cancer by $9 \%$ in case-control studies. ${ }^{10,11}$ Moreover, disturbed circadian rhythms in shift workers or emergency physicians also are associated with metabolic syndrome or altered telomerase activities. ${ }^{12,13}$

Several important kidney functions, such as glomerular filtration rate, renal blood flow, urine production, and electrolyte balance, have daily oscillation rhythms. ${ }^{9}$ The amplitude of the melatonin oscillating rhythm decreases as renal disease advances. The disturbed melatonin rhythm in patients with chronic kidney disease is associated with sleep disorders and can be restored by changing dialysis timing. ${ }^{14}$ Substantial evidence links aldosterone signaling to disruption of the circadian blood pressure pattern, ${ }^{15,16}$ suggesting the roles of renal function and circadian rhythm. BMAL1 deficiency in the renin-secreting granular cells of the juxtaglomerular apparatus results in altered urine volume, changes in urinary sodium excretion, and lower blood pressure. CLOCK deficiency in mice also causes dramatic changes in the circadian rhythm of renal sodium excretion through 20-hydroxyicosatetraenoic acid. ${ }^{17,18}$ This evidence supports a link between circadian rhythm and renal function. However, whether disturbed circadian rhythm is involved in the progression of renal dysfunction or increases in the incidence of chronic kidney diseases is unknown.

Tubulointerstitial fibrosis is one of the most common histopathologic features of progressive renal disease. Irreversible renal fibrosis leads to deterioration and loss of kidney function. Clock gene PER 2 deficiency or mutation exacerbates liver fibrosis and increases vascular senescence. ${ }^{12,19}$ Based on all of the evidence, we hypothesized that CLOCK-deficient mice would have altered fibrotic responses after unilateral ureteral obstruction.

\section{Materials and Methods}

\section{Cells and Antibody}

Proximal tubular epithelial cells were isolated from wildtype or CLOCK-deficient mice. The kidneys were de-capsulated and the medulla was removed. The cortices were finely dissected and digested with collagenase. The kidney digests were filtered through a $70-\mu \mathrm{m}$ sieve (BD Biosciences, San Jose, CA) and cell pellets were resuspended in a renal cell culture medium (Dulbecco's modified Eagle's medium-F12, $10 \%$ fetal bovine serum, $5 \mu \mathrm{g} / \mathrm{mL}$ insulin, $5 \mu \mathrm{g} / \mathrm{mL}$ transferrin, $50 \mathrm{nmol} / \mathrm{L}$ selenium, $5 \mathrm{nmol} / \mathrm{L}$ $\mathrm{T} 3,50 \mathrm{mmol} / \mathrm{L}$ hydrocortisone, and $100 \mathrm{U} / \mathrm{mL}$ penicillin/ $0.1 \mathrm{mg} / \mathrm{mL}$ streptomycin). Mouse embryonic fibroblasts (MEFs) were isolated from day 11 to day $13 \mathrm{C} 57 \mathrm{BL} / 6 \mathrm{~J}$ mouse embryos using the trypsin method. ${ }^{20}$ To assess the oscillation of gene expression, cells were synchronized using serum shock. The antibodies that were used for immunoblotting and immunofluorescence were $\alpha$-smooth muscle actin (Sigma, St. Louis, MO), glyceraldehyde-3phosphate dehydrogenase (Cell Signaling, Danvers, MA), 4-hydroxynonenal (R\&D Systems), nitrotyrosine (R\&D Systems, Minneapolis, MN), cyclooxygenase (COX)1 (Cell Signaling), and COX2 (Cell Signaling).

\section{Mice and Unilateral Ureteral Obstruction}

All animal experiments were approved and performed in accordance with the guidelines of Chang Gung University and the Chang Gung Memorial Hospital Institutional Animal Care and Use Committee. CLOCK-deficient mice on a C57BL/6J background were a gift from Drs. Steven M. Reppert and David R. Weaver (University of Massachusetts Medical School, Worcester, MA). The mPer2 $2^{\text {Luciferase }}$ knock-in mice were obtained from Jackson Laboratory (Bar Harbor, ME). Congenic 8- to 12-week-old, male, wild-type, and CLOCK-deficient littermate mice were generated from heterozygote breedings and were used for all studies. The unilateral ureteral obstruction (UUO) procedure was performed under general anesthesia with ketamine and xylazine (80/6 $\mu \mathrm{g} / \mathrm{g}$ intraperitoneally, respectively). An incision was made in the left flank area using a scalpel. Ureters then were explored and ligated using 2-0 silk with a double ligature. ${ }^{21}$ After ligation, the surgical fields were rinsed with sterile phosphate-buffered saline to prevent future adhesion. After 7 or 14 days, mice were sacrificed and kidneys were harvested for further analysis. The right kidneys served as controls.

\section{Kidney Pathology}

The UUO or control kidneys were fixed in $4 \%$ paraformaldehyde and paraffin-embedded. Tissue sections with a thickness of $5 \mu \mathrm{m}$ were obtained. Paraffin wax was removed using xylene and the sections were rehydrated with ethanol. After washing, the sections were stained with hematoxylin and eosin. To determine the degree of tubulointerstitial collagen deposition, sections were stained using a modified Picrosirius Red Stain Kit (24901; Polysciences, Inc., Warrington, PA). All cortical tubulointerstitial fields were examined at $\times 400$ magnification with Adobe Photoshop CS2 (Adobe, San Jose, CA) and ImageJ version 1.49a (NIH, Bethesda, MD).

\section{Real-Time Bioluminescence Assays}

The $m P e r 2^{\text {Luciferase }}$ mice underwent UUO surgeries within the first 2 hours after lights-on and were sacrificed 7 days later simultaneously within the first 2 hours after lights-on. Kidneys with UUO and the contralateral control kidneys from the same animals were dissected and cultured as described previously. ${ }^{22}$ Organ explants were dissected to approximately $5 \mathrm{~mm}^{2}$ and each was placed individually in a culture well with luciferin. Luciferase activities were recorded for 1 minute at 15-minute intervals with an LM2400 
luminometer (Hamamatsu, Hamamatsu City, Japan). ${ }^{23}$ Explants with low levels $(<6000 \mathrm{cpm})$ were excluded. Period and phase values were calculated as in previous studies. ${ }^{22,24}$ The raw data were smoothed by an adjacent-averaging method. The peak was measured as the highest point of the smoothened data. The period was computed as the mean between the peaks.

\section{Transcriptional Analysis}

Promoter activities were analyzed in renal tubular cells or macrophages from wild-type or CLOCK-deficient mice. Cells $\left(4 \times 10^{5}\right)$ were seeded in 6-well plates and transfected with $m P e r 2$-luc, transforming growth factor (TGF)- $\beta 1$-luc, or $T G F-\beta 1-$ luc without E-box reporter plasmids with FuGENE HD (Roche, Indianapolis, IN). The pRL-SV40 plasmid that contained Renilla luciferase was used to control for differences in transfection efficiency. The cells were lysed 48 hours after transfection and analyzed with a dual-luciferase reporter assay system (Promega, Madison, WI). Chromatin immunoprecipitation (ChIP) was performed with whole kidneys (30 mg per final ChIP) or renal tubular cells that were isolated from the kidneys at each circadian time point with $1 \%$ formaldehyde. Cross-linking reactions were stopped by adding $150 \mathrm{mmol} / \mathrm{L}$ glycine. The homogenate then was layered on top of $10 \mathrm{~mL}$ of $2.05 \mathrm{~mol} / \mathrm{L}$ sucrose and centrifuged for 30 minutes at $1500 \times \mathrm{g}$ at $1{ }^{\circ} \mathrm{C}$. The nuclei were resuspended in $1 \mathrm{~mL}$ of $20 \mathrm{mmol} / \mathrm{L}$ Tris, pH 7.5, $150 \mathrm{mmol} / \mathrm{L} \mathrm{NaCl}, 2 \mathrm{mmol} / \mathrm{L}$ EDTA, and sedimented at $1500 \mathrm{~g}$. The nuclei then were lysed with a radioimmunoprecipitation assay buffer and sonicated for 15 seconds on ice 10 times. Duplicate ChIPs were performed using three animals per time point, using an antibody against CLOCK (Abcam, Cambridge, MA). The mouse TGF- $\beta 1$ ChIP primers were as follows: forward 5'-TGCTACTAATCGCCATCATCC-3', and reverse 5'-CCCTTTCTACCCCGTAGTTCA- $3^{\prime}$. Primers for regions downstream of the $T G F b 1$ promoter were used as a negative control. The results were normalized to the input control without immunoprecipitation.

\section{RNA Expression and Protein Analysis}

Total RNA was extracted using TRI Reagent (Ambion, Foster City, CA) according to the manufacturer's instructions. One microgram of total RNA was reversetranscribed and analyzed using the Applied Biosystems Real-Time PCR System. The relative gene expression method was used for analysis, and the expression of the target genes was normalized to that of $18 \mathrm{~S}$ rRNA. The assay was repeated independently at least three times. Protein was isolated from homogenized frozen kidneys or cells with a cell lysis buffer (Cell Signaling). The lysates were separated by electrophoresis, transferred to polyvinylidene fluoride membranes, and probed with specific antibodies. The results were normalized to the glyceraldehyde-3-phosphate dehydrogenase band and calculated with ImageJ version $1.49 \mathrm{a}(\mathrm{NIH})$.

\section{Lucigenin Assay}

The production of $\mathrm{O}_{2}{ }^{-}$by renal tubular cells was measured using lucigenin-enhanced chemiluminescence in a microplate luminometer. The lucigenin concentration $(5 \mu \mathrm{mol} / \mathrm{L})$ was used to minimize background and redox cycling. Proteins were diluted in modified HEPES buffer and loaded $(100 \mu \mathrm{g} /$ well) onto a 96-well microplate. NADPH (100 $\mu \mathrm{mol} / \mathrm{L})$ and dark-adapted lucigenin were added to wells just before reading. The production of $\mathrm{O}_{2}{ }^{-}$was expressed in arbitrary light units over 20 minutes. Some experiments were performed in the presence of superoxide dismutase (SOD, $200 \mathrm{U} / \mathrm{mL}$ ) or a cell-permeable superoxide scavenger tiron $(10 \mathrm{mmol} / \mathrm{L})$ for control experiments.

\section{Celecoxib Treatment}

After undergoing UUO surgery, the CLOCK-deficient mice were divided randomly into a control group $(n=8)$ and a treatment group $(n=8)$. One day after surgery, the mice in the treatment group received $200 \mathrm{mg} / \mathrm{kg}$ celecoxib (Pfizer, Taipei, Taiwan) and the mice in the control group received water via oral feeding daily for 6 days at circadian time 1 . The mice were sacrificed on day 7 at circadian time 1 and analyzed. The analyzer and feeder were blinded to the treatment of the mice.

\section{Statistical Analysis}

Data were evaluated using two-way analysis of variance or the Student's $t$-test. A $P$ value $<0.05$ was considered statistically significant.

\section{Results}

Ureteral Obstruction Results in Increased Amplitude of Circadian Gene Oscillation

To analyze the change in circadian rhythm in the kidney that is caused by ureteral obstruction, we performed UUO in the $m P e r 2^{\text {Luc }}$ knock-in mice. The $m P e r 2^{\text {Luc }}$ knock-in mice expressed mPERIOD2::LUCIFERASE fusion proteins, which served as a real-time reporter for circadian rhythm oscillation. ${ }^{24}$ Seven days after UUO surgery, kidneys with ureteral obstruction and contralateral kidneys with sham surgery were isolated and luminescence was measured continuously in real time using an LM-2400 detector (Hamamatsu, Hamamatsu City, Japan). ${ }^{23}$ Consistent with a previous report, ${ }^{23}$ a robust and sustained circadian rhythm of luminescence was found in kidneys with sham surgery over the 7-day period. In the ureteral-obstructed kidneys, we observed a significantly higher level and oscillatory amplitude of mPEROID2::LUCIFERASE luminescence than in the kidneys with sham surgery (Figure 1A).

To confirm the increased expression and amplitude of oscillation of the circadian gene in ureteral-obstructed kidneys, 
A

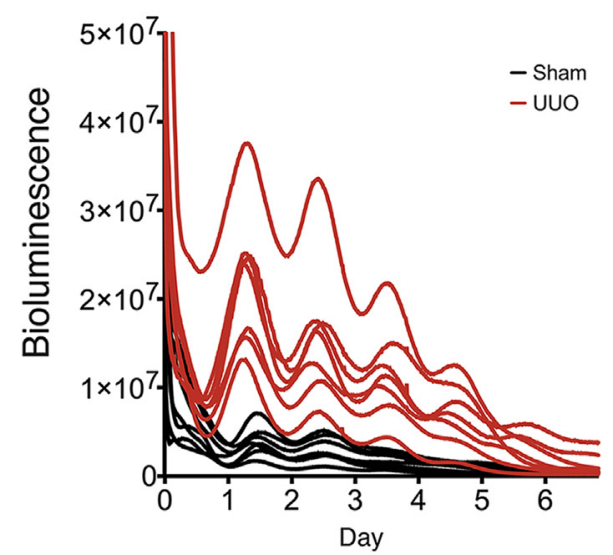

B

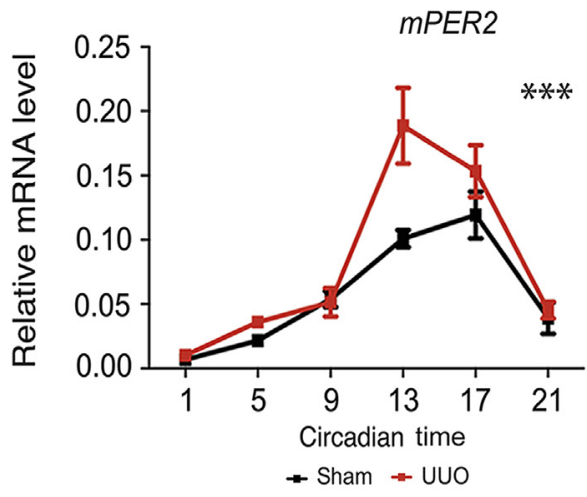

C

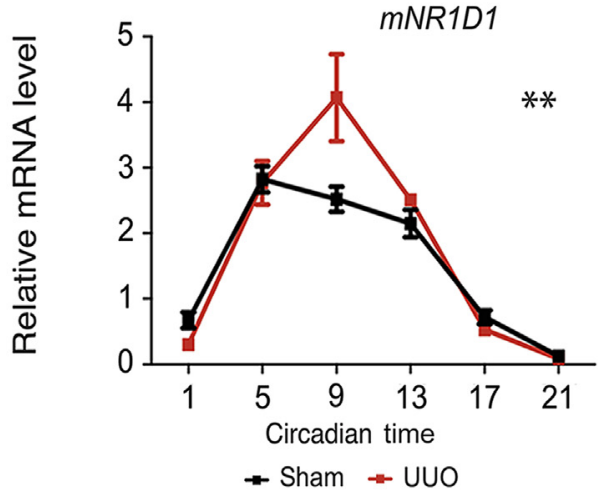

D

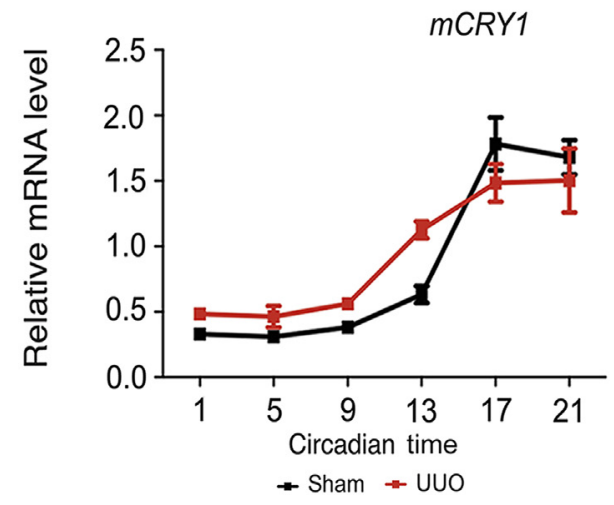

we examined the mRNA expression levels in the kidneys with or without UUO surgery. Mice were sacrificed 7 days after UUO surgery at 4-hour intervals around the clock and kidney RNA was prepared and analyzed. The results showed that the mPER2, mNR1D1, and mCRY1 mRNA accumulated in a circadian manner in both the UUO kidneys and the sham kidneys. Consistent with luminescence experiments, mPER2, mNR1D1, mBMAL1, and mCLOCK mRNA expression in the UUO kidneys was higher and showed a larger amplitude of oscillation than in the sham kidneys (Figure 1, B and C, and Supplemental Figure S1). Moreover, UUO significantly increased CLOCK protein levels (Supplemental Figure S2). No significant difference in mCRY1 mRNA accumulation was found between UUO and sham kidneys (Figure 1D). These data showed that the circadian gene oscillatory rhythm in kidneys was altered significantly by ureteral obstruction. Therefore, we hypothesized that a deficiency of the circadian gene can affect the process of UUO in mice. Because the UUO significantly increased the level of CLOCK protein, CLOCKdeficient mice, which had near-normal central circadian clock rhythm and locomotor activities, were chosen to verify our hypothesis. ${ }^{22}$ Normal locomoter activities in CLOCK-deficient mice excluded the influences of altered food intake rhythm or disturbed hormonal rhythm, such as glucocorticoid or interferon. ${ }^{25,26}$

\section{Renal Fibrosis Is More Severe in CLOCK-Deficient Mice with UUO}

We performed UUO surgery on wild-type and CLOCKdeficient mice and analyzed the extent of renal fibrosis development 7 days after surgery. Consistent with previous studies, $^{21}$ the wild-type mice developed significant hydronephrosis, cortical thinning, and tubular atrophy. Gross examination of the UUO kidneys of CLOCK-deficient mice showed extensive fibrosis around perirenal tissues in 8 of the 10 mice, and none in wild-type mice (Figure 2A). Moreover, CLOCK-deficient mice showed significantly exacerbated renal injury, as shown by increased hydronephrosis, tubular atrophy, and cortical thinning relative to wild-type mice. Interstitial collagen deposition on picrosirius red staining was significantly higher in CLOCK-deficient mice after UUO than in wild-type mice (Figure 2, B and C). There were no significant differences in the numbers of tubular cells, leukocytes, and endothelial cells between wild-type and CLOCK-deficient mice after UUO (Supplemental Figure S3).

\footnotetext{
Figure 1 Circadian gene oscillation amplitudes increase after ureteral obstruction. A: Representative records of real-time bioluminescence from kidneys that were isolated from mPer2 ${ }^{\text {Luc }}$ knock-in mice after sham or unilateral ureteral obstruction (UUO) surgery. Relative mRNA levels of mPER2 (B), mNR1D1 (C), and $m C R Y 1$ (D) from kidneys that were isolated from wild-type mice after sham or UUO surgery. Data are presented as means \pm SEM. $n=6$ mice per time point. ${ }^{* * P}<0.01,{ }^{* * * P}<0.001$ by one-way analysis of variance and Bonferroni post hoc test.
} 
A
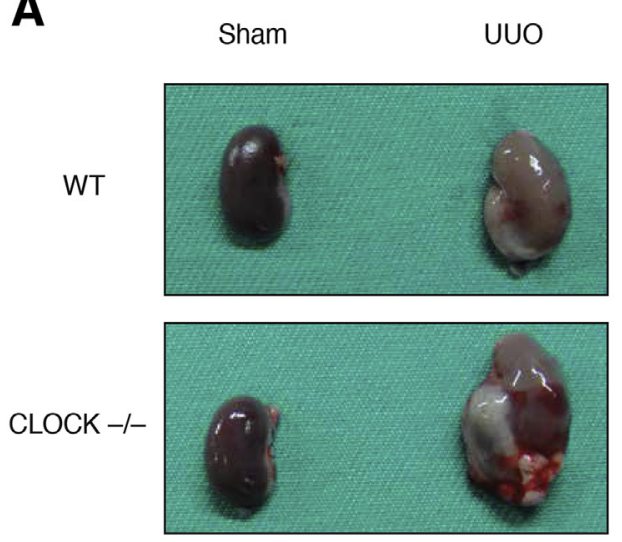

B
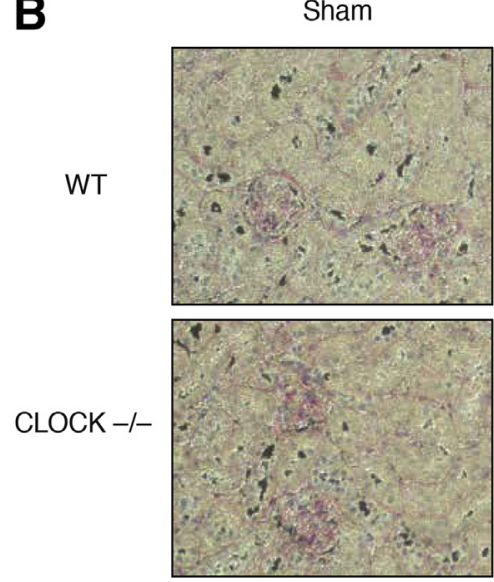

UUO



C

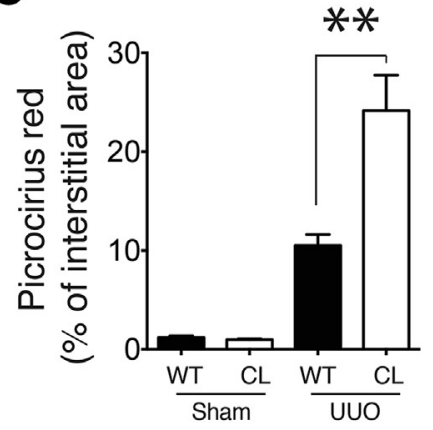

D

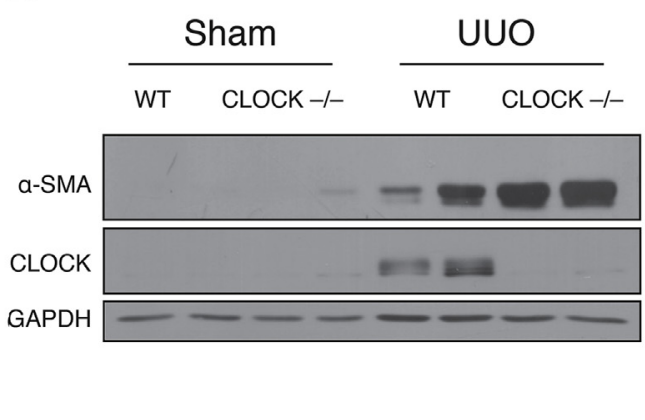

E

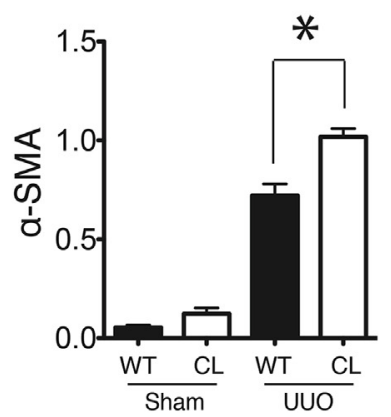

Figure 2 Effects of CLOCK (CL) deficiency on tubulointerstitial fibrosis in mice. A: Photograph of kidneys from wild-type (WT) and CLOCK-deficient mice after unilateral ureteral obstruction (UUO) surgery. Right obstructed kidney or left nonobstructed kidney were removed 7 days after UU0. B: Representative picrosirius red staining of WT and CLOCK-deficient kidney sections for assessment of total collagen deposition and extent of fibrosis. C: Quantitative analysis of collagen deposition in WT and CLOCK-deficient mice. Representative Western blot images (D) and densitometric quantification (E) of $\alpha$-smooth muscle actin ( $\alpha$-SMA) protein levels from mice kidneys. Data are presented as means \pm SEM. Data were analyzed using two-way analysis of variance followed by a Tukey post hoc test. $n=10 .{ }^{*} P<0.05,{ }^{*} P<0.01$ CLOCK UU0 versus WT UU0. Original magnification, $\times 100$ (B). GAPDH, glyceraldehyde 3-phosphate dehydrogenase.

Consistent with this observation, $\alpha$-smooth muscle actin mRNA and protein levels, which are indices of the proliferation of activated myofibroblasts, were higher in CLOCKdeficient mice (Figure 2, D and E, and Figure 3A). Levels of extracellular matrix-related mRNA of Col1A1, Col4A1, and connective tissue growth factor were significantly higher in CLOCK-deficient mice (Figure 3, B-D). UUO reduced the expression of bone morphogenetic protein-7, which plays a protective role in renal fibrosis, but no significant difference was observed between CLOCK-deficient and wild-type mice (Figure 3E). The expression of TGF- $\beta$ was increased significantly in the CLOCK-deficient UUO kidneys (Figure 3F). These results provide evidence that CLOCK deficiency accelerates renal tubulointerstitial fibrosis in mice after UUO.

\section{TGF- $\beta$ mRNA Expression Shows Circadian 0scillation and Is Regulated by CLOCK-BMAL1 Heterodimers}

The increased TGF- $\beta$ expression intrigued us. TGF- $\beta$ is one of the most important factors in the pathogenesis of progressive kidney disease. ${ }^{27,28}$ TGF- $\beta$ promotes apoptosis or epithelialmesenchymal transition of tubular epithelial cells, which lead to abnormal deposition of the ECM and interstitial fibrosis. ${ }^{29,30}$ In light of evidence that CLOCK-deficient kidneys showed increased TGF- $\beta$ levels after UUO, we hypothesized that TGF- $\beta$ is a clock-controlled gene. To determine whether TGF- $\beta$ expression shows circadian rhythms, we first examined the temporal expression of TGF- $\beta$ mRNA in serumsynchronized cultured MEFs from wild-type and CLOCKdeficient mice. The results thus obtained showed that TGF- $\beta$ mRNA accumulated in a circadian manner in wild-type MEFs (Figure 4A) and in CLOCK-deficient MEFs, TGF- $\beta$ mRNA levels were significantly lower and without a circadian rhythmicity (Figure 4A).

The mouse TGF- $\beta$ gene has a CLOCK-BMAL1 E-box site near the $5^{\prime}$ end of the gene, similar to other clockregulated genes (Figure 4B). ${ }^{31}$ To determine whether CLOCK-BMAL1 heterodimers regulate TGF- $\beta$ mRNA expression by modulating TGF- $\beta$ promoter activity, we first tested the TGF- $\beta$ promoter responses to CLOCK or BMAL1 with luciferase assay. CLOCK or BMAL1 alone increased the TGF- $\beta$ promoter activity by twofold. Cotransfection of CLOCK and BMAL1 together increased TGF- $\beta$ promoter activity by approximately threefold (Figure 4, C and D). 
A

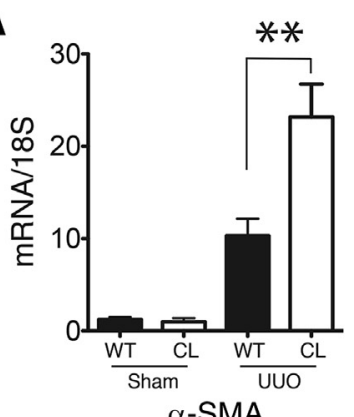

$\alpha-S M A$

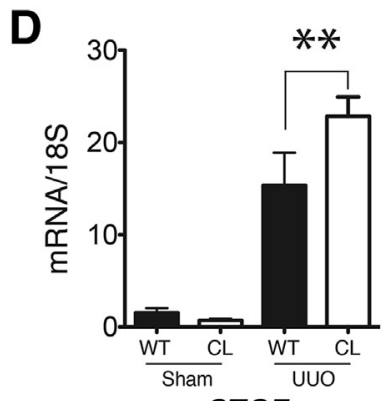

CTGF
B

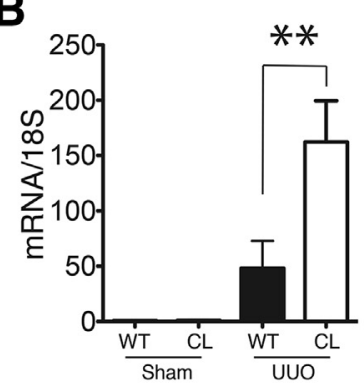

Col1A1

E

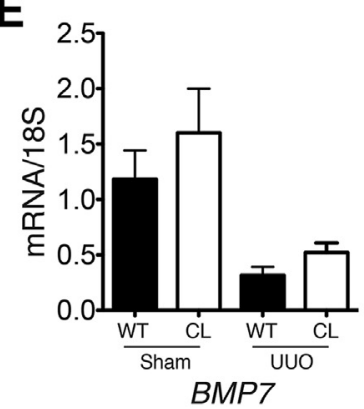

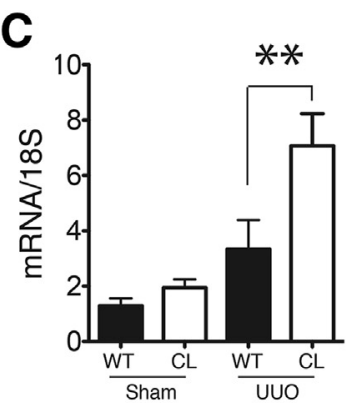

Col4A1

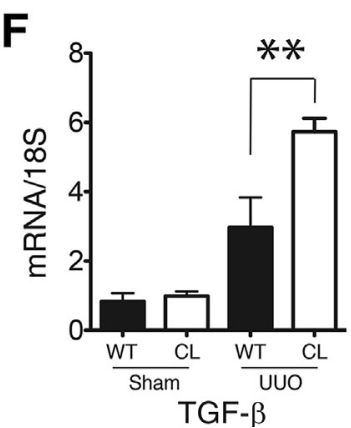

Figure 3 Effects of CLOCK (CL) deficiency on gene expressions after tubulointerstitial fibrosis. Relative mRNA levels in kidneys from wild-type (WT) and CLOCK-deficient mice after sham or ureteral obstruction. $\alpha$-Smooth muscle actin $(\alpha-S M A, A)$; type I collagen, $\alpha 1$ (Col1A1, B); type IV collagen, $\alpha 1$ (Col4A1, C); connective tissue growth factor (CTGF, D); bone morphogenetic protein $7(B M P 7, E)$; and transforming growth factor- $\beta$ (TGF- $\beta$, F). Data are presented as means \pm SEM. Data were analyzed using two-way analysis of variance followed by a Tukey post hoc test. $n=6 .{ }^{* *} P<0.01$ CLOCK UUO versus WT UUO.
Mutation analysis showed that TGF- $\beta$ promoter without an E-box failed to respond to the transactivation of CLOCK and BMAL1 (Figure 4E). Whether CLOCK-BMAL1 could bind to the TGF- $\beta$ promoter in vivo then was examined. ChIP assays were performed with nuclear extracts that were obtained from mouse kidney tubular cells at different circadian times. The binding of CLOCK to the mouse TGF- $\beta$ promoter was robust and showed a significant circadian rhythm, with its highest peak at circadian time 5 (Figure 4F). These results indicated that TGF- $\beta$ is a clock-controlled gene and its circadian rhythm is lost in CLOCK-deficient MEFs.
A

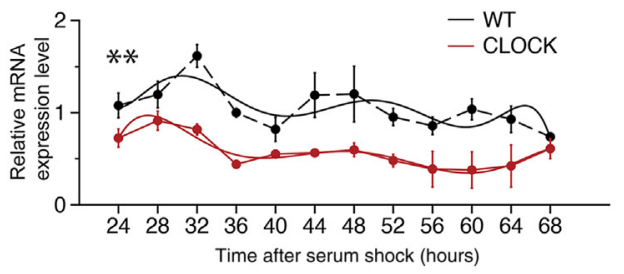

C

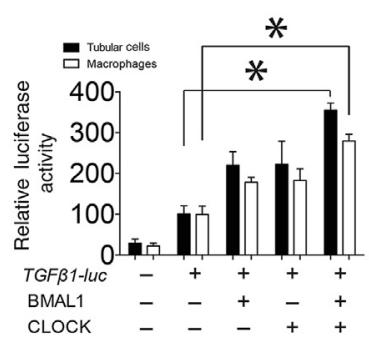

$\mathbf{E}$

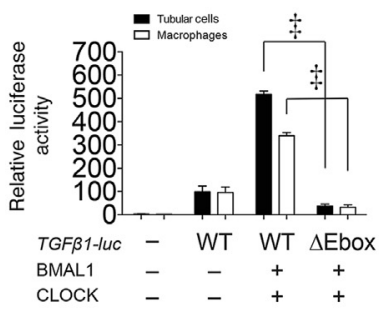

$\mathbf{B}_{-651}$ TGAAGCAGGCACGTGGACTCTGGAG
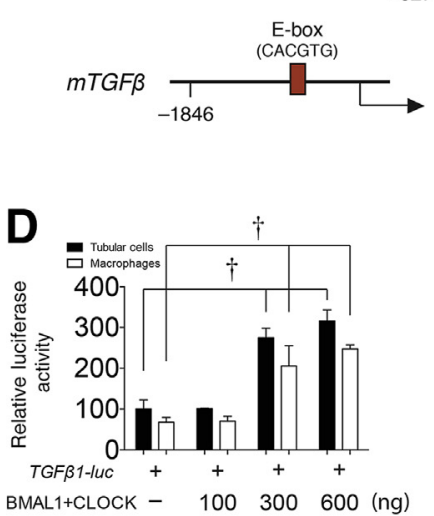

$\mathbf{F}$

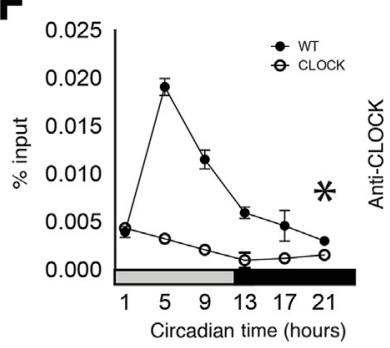

Figure 4 Circadian transactivation of transforming growth factor- $\beta$ (TGF- $\beta$ ) (Tgfb1) promoter by CLOCK-BMAL1 heterodimers. A: Accumulation of TGF- $\beta$ mRNAs in serum-shocked mouse embryonic fibroblasts from wild-type (WT) or CLOCK-deficient mice. Circadian rhythmicity was analyzed with JTK_CYCLE. B: Schematic diagram of mouse TGF- $\beta$ promoters and E-boxes. C: Effect of CLOCK and BMAL1 on the transactivation of mouse TGF (mTGF) $\beta$ promoter in renal tubular cells and macrophages. D: Dose-dependent effect of CLOCKBMAL1 heterodimers on the transactivation of $m T G F-\beta$ promoter in renal tubular cells and macrophages. E: Effects of CLOCK-BMAL1 heterodimers on the transactivation of $m$ TGF- $\beta$ promoter with E-box deletion ( $\Delta$ Ebox). F: Binding of CLOCK to $m$ TGF- $\beta$ promoters in mouse renal tubular cells analyzed by chromatin immunoprecipitation. Data are presented as means \pm SEM. Circadian rhythmicity was analyzed with JTK_CYCLE. Data were analyzed using two-way analysis of variance followed by a Tukey post hoc test. $n=3(\mathbf{A}, \mathbf{D}, \mathbf{E}$, and $\mathbf{F}) ; n=4(\mathbf{C}) .{ }^{*} P<0.05$ TGF- $\beta$-luc without BMAL1+CLOCK versus TGF- $\beta$-luc with BMAL1+CLOCK; ${ }^{*} P<0.01$ (WT) and $P=0.23$ (CLOCK) ${ }^{\dagger} P<0.05$ BMAL1+CLOCK 300 or $600 \mathrm{ng}$ versus no BMAL1+CLOCK; and ${ }^{\ddagger} P<0.05 \Delta$ Ebox versus WT. 
WT sham

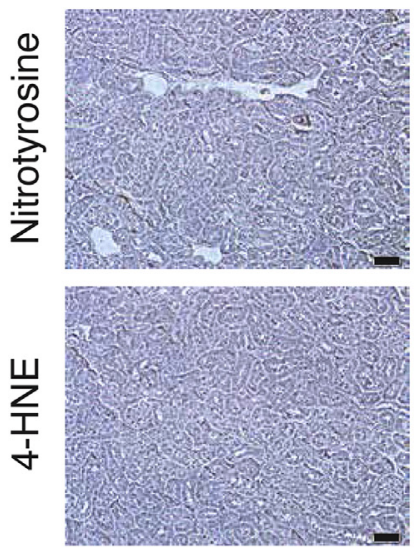

WT UUO
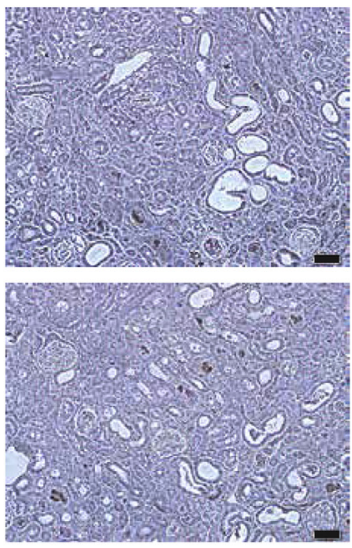

CLOCK sham
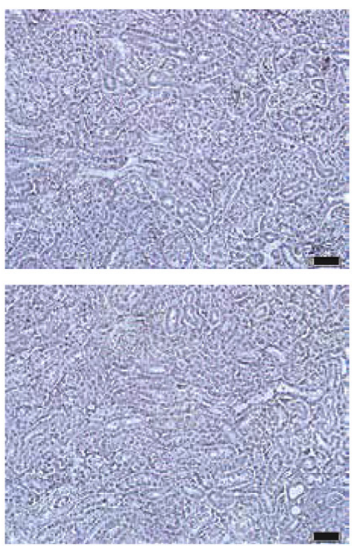

CLOCK UUO
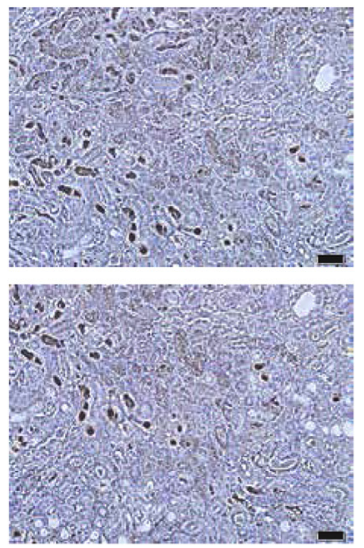

Figure 5 0xidative injury markers increase in CLOCK-deficient mice. Immunohistochemical staining of oxidative stress markers 4-hydroxynonenal (4-HNE) and nitrotyrosine in consecutive kidney sections of wild-type (WT) and CLOCK-deficient mice $(n=6)$. Scale bar $=50 \mu \mathrm{m}$. UU0, unilateral ureteral obstruction.

\section{Increased 0xidative Stress in CLOCK-Deficient Mice after UU0}

Uncontrolled renal fibrosis is detrimental and may lead to endstage renal disease. Currently, no effective treatment reverses renal fibrosis. TGF- $\beta$ plays a fundamental role in the homeostasis of fibrosis signaling. However, direct TGF- $\beta$ signaling intervention is not sensible because it is involved in multiple crucial physiological processes. ${ }^{32}$ Evidence has suggested that reactive oxygen species and related signaling could be critical
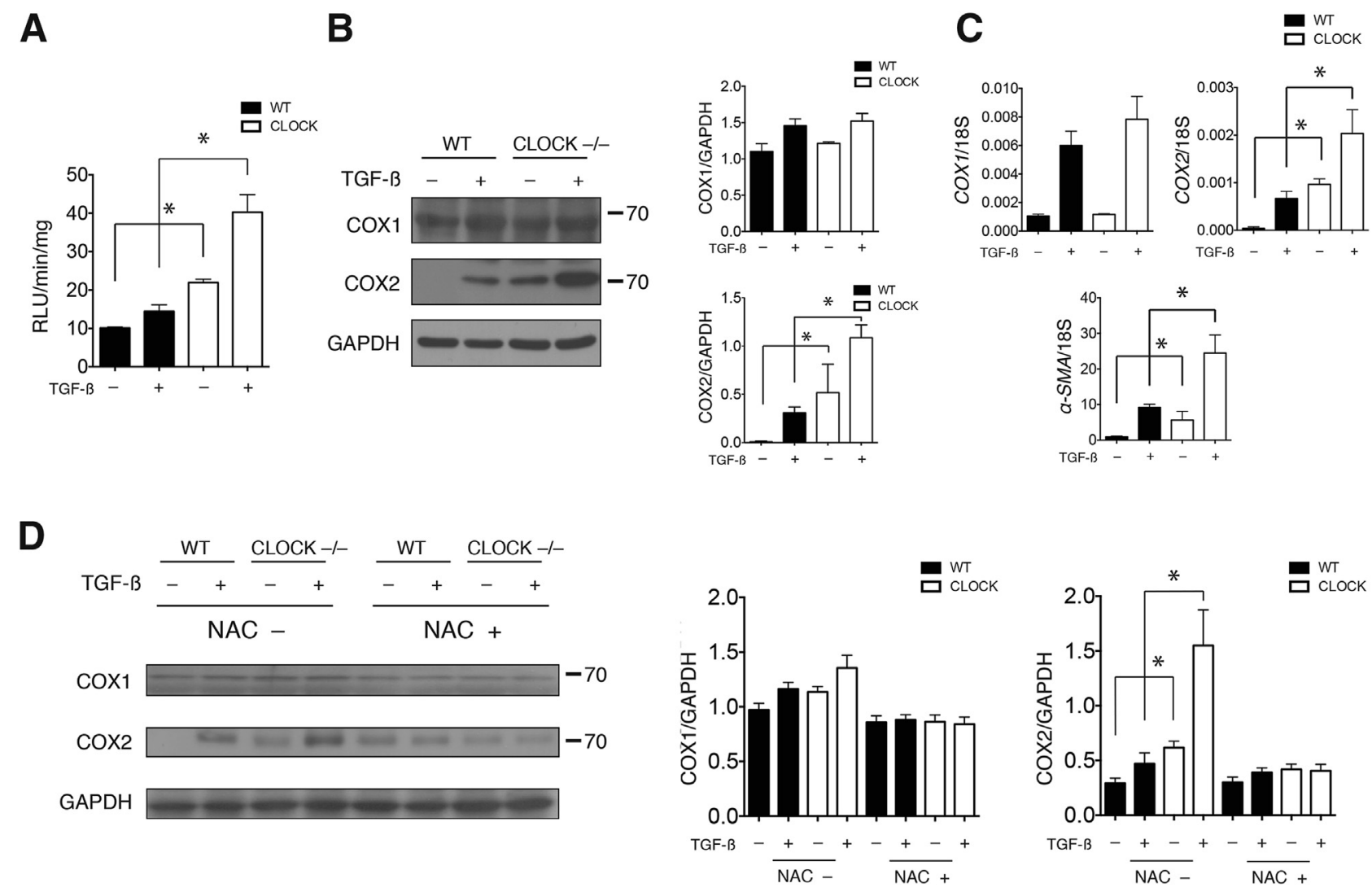

Figure 6 0xidative stress and cyclooxygenase (COX)2 levels increase in CLOCK-deficient mice. A: NADPH oxidase activity was measured by lucigenin assay in wild-type (WT) or CLOCK-deficient renal tubular cells with or without transforming growth factor (TGF)- $\beta$ treatment (2 ng/mL, 8 hours). B and C: COX1 and COX2 protein and mRNA levels in WT and CLOCK-deficient renal tubular cells with or without TGF- $\beta$ treatment. D: COX1 and COX2 protein and mRNA levels in wild-type and CLOCK-deficient renal tubular cells with or without preincubation with $1 \mathrm{mmol} / \mathrm{L}$ n-acetyl cysteine (NAC) for 1 hour and treatment with TGF- $\beta$, as indicated. Data are presented as means \pm SEM. Data were analyzed using two-way analysis of variance followed by a Tukey post hoc test. $n=4$ (B-D). ${ }^{*} P<0.05$ CLOCK versus WT. GAPDH, glyceraldehyde-3-phosphate dehydrogenase; RLU, relative light unit. 
A

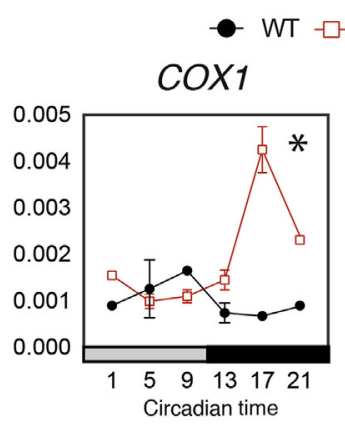

B

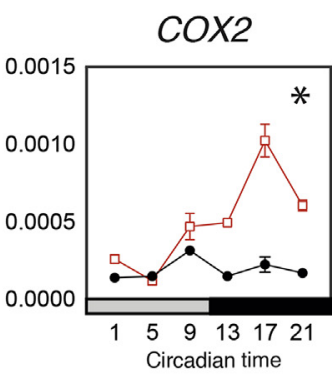

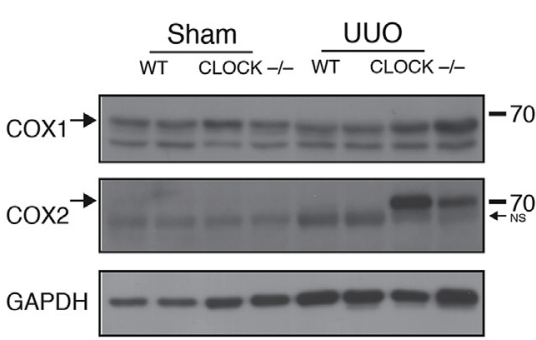

GAPDH $-(-2-\infty-\infty=0$

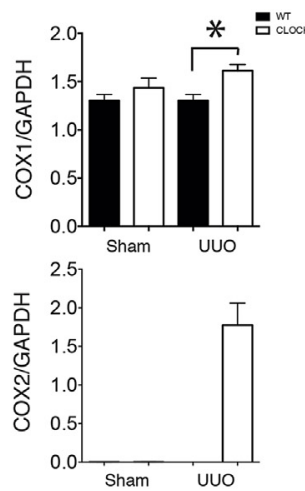

C

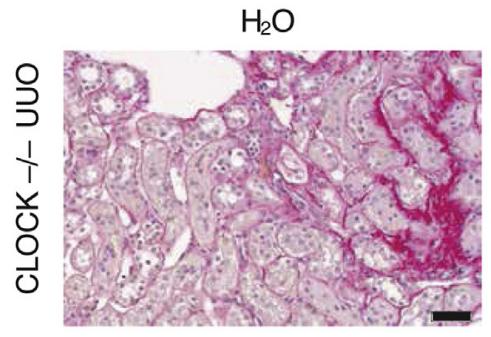

Celecoxib

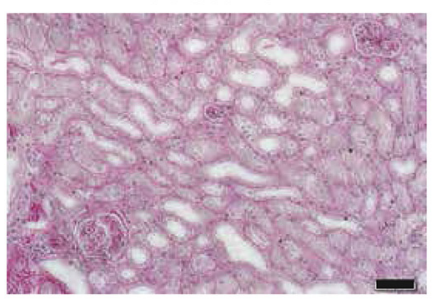

D
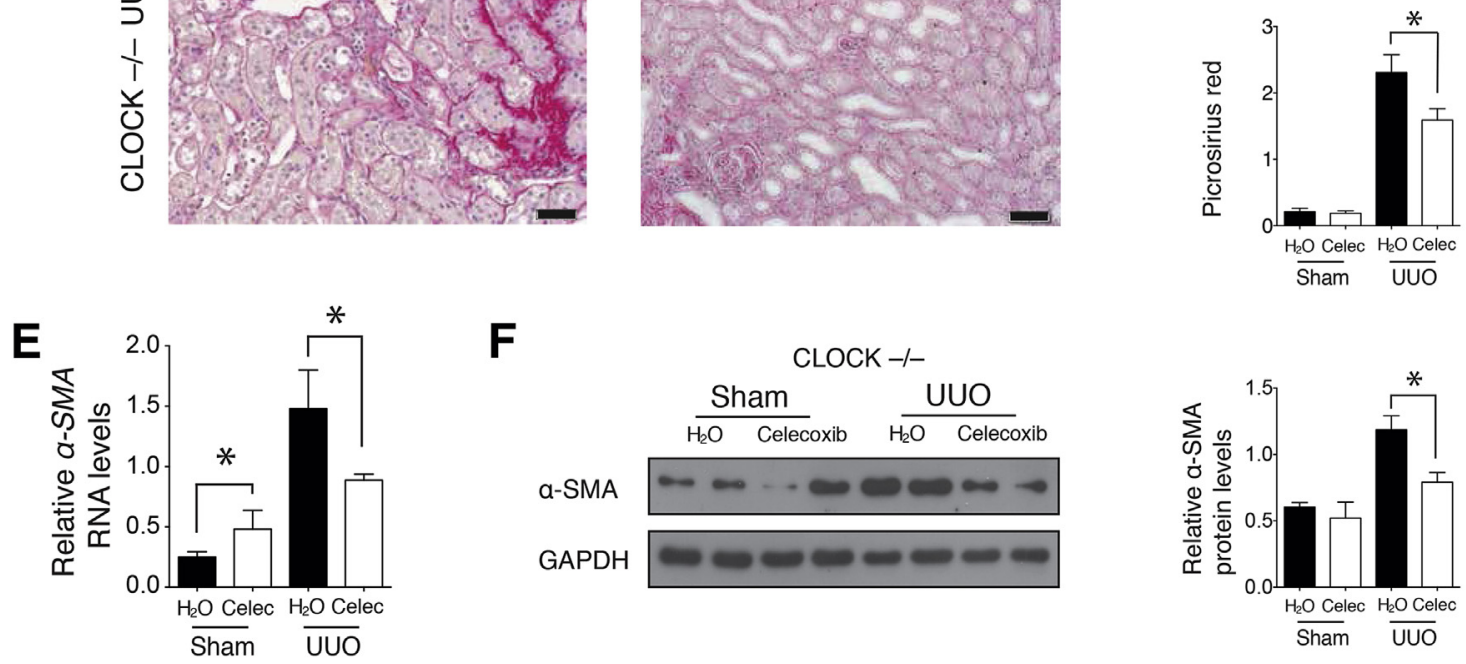

$\mathbf{F}$

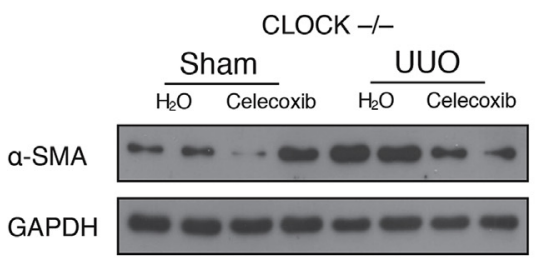

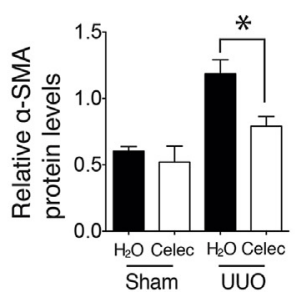

Figure 7 Cyclooxygenase 2 inhibition rescues the tubulointerstitial fibrosis after unilateral ureteral obstruction (UU0) surgery in CLOCK-deficient mice. A: Accumulation of COX1 and COX2 mRNAs in the kidneys from wild-type (WT) or CLOCK-deficient mice. B: Representative Western blot images and analysis of COX1, COX2, and glyceraldehyde-3-phosphate dehydrogenase (GAPDH) in kidneys from wild-type or CLOCK-deficient mice after sham or UU0 surgery. C: Representative picrosirius red staining. D: Quantitative analysis of CLOCK-deficient kidney sections for assessment of total collagen deposition and extent of fibrosis after UUO surgery and treatment with $\mathrm{H}_{2} \mathrm{O}$ or celecoxib. E: Relative $\alpha$-smooth muscle actin ( $\alpha$-SMA) mRNA levels in CLOCK-deficient kidneys after sham or UUO surgery and treatment with $\mathrm{H}_{2} \mathrm{O}$ or celecoxib. F: Analysis of $\alpha$-SMA protein levels in CLOCK-deficient kidneys after sham or UUO surgery and treatment with $\mathrm{H}_{2} \mathrm{O}$ or celecoxib. Data are presented as means \pm SEM. Data were analyzed using two-way analysis of variance followed by a Tukey post hoc test. $n=3$ $(\mathbf{A}$ and $\mathbf{B}) ; n=4(\mathbf{F}) ; n=6(\mathbf{E}) ; n=8$ (D). ${ }^{*} P<0.05$ CLOCK versus WT. Scale bar $=50 \mu \mathrm{m}$. Celec, celecoxib.

downstream mediators in renal fibrosis. ${ }^{21,33}$ Accordingly, we hypothesized that the exacerbation of fibrosis in CLOCKdeficient mice may be a result of the increased formation of reactive oxygen species. To evaluate oxidative stress in the kidney after UUO, we performed immunohistochemical staining of nitrotyrosine. In CLOCK-deficient mice, UUO significantly increased the number of nitrotyrosine-positive tubules (positive tubules/field: wild-type UUO $7.9 \pm 1.2$ versus CLOCK UUO $39.6 \pm 11.1 ; n=6 ; P<0.05$ ) (Figure 5) and the amount of another oxidative stress marker, 4-hydroxynonenal (positive tubules/field: wild-type UUO $5.1 \pm 1.2$ versus CLOCK UUO $19.2 \pm 7.3 ; n=6 ; P<0.05$ ) (Figure 5). These data supported increased oxidative stress in CLOCK-deficient mice.

We further studied the oxidative stress in CLOCKdeficient renal tubular cells. TGF- $\beta$ treatment increased the lucigenin activity and oxidative stress in wild-type renal tubular cells. CLOCK-deficient renal tubular cells showed higher lucigenin activity without TGF- $\beta$ treatment than wildtype renal tubular cells. TGF- $\beta$ treatment significantly increased lucigenin activity in CLOCK-deficient renal tubular cells (Figure 6A). COX1 and COX2 convert arachidonic acid to prostaglandin. ${ }^{34} \mathrm{COX} 1$ is responsible for the control of renal hemodynamics and glomerular filtration rate. ${ }^{35} \mathrm{COX} 2$ is inducible in response to inflammation or injury in kidney and affects salt and water handling. ${ }^{36}$ Selective inhibition of COX2 reduces proteinuria after $5 / 6$ renal ablations in mice, inhibits nephritis in rats, and reduces both renal fibrosis and TGF- $\beta$ levels in rats after UUO. ${ }^{37,38}$ Based on the observation that CLOCK deficiency increased oxidative stress, we hypothesized that CLOCK deficiency would affect COX1 and COX2 levels in renal tubular cells. After treatment with TGF- $\beta$, CLOCK-deficient renal tubular cells had significantly 


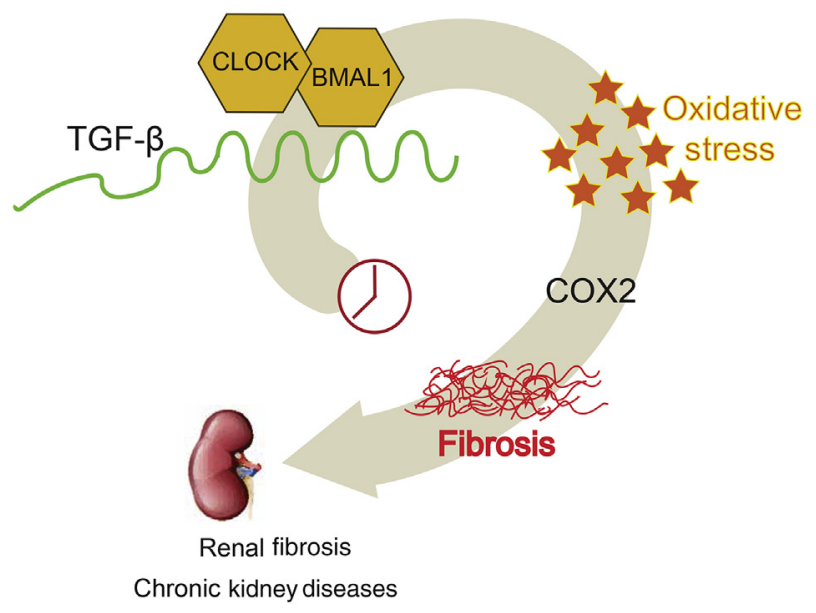

Figure 8 A model illustrating the circadian rhythm control of transforming growth factor (TGF)- $\beta$ and cyclooxygenase (COX)2 signaling axis. Loss of CLOCK leads to circadian disruption of TGF- $\beta$ oscillation and increased oxidative stress in kidneys. Increased COX2 after oxidative stress results in enhanced renal fibrosis and chronic kidney diseases.

higher COX2 protein and mRNA levels than wild-type cells (Figure 6, B and C).

To test the mechanism that links CLOCK deficiency to increased oxidative stress and increased COX2, we assessed whether the preincubation of CLOCK-deficient renal tubular cells with $1 \mathrm{mmol} / \mathrm{L}$ n-acetyl-cysteine, which is an antioxidant that scavenges reactive oxygen species, suffices to affect COX2 levels. After incubation with n-acetyl cysteine, CLOCK-deficient renal tubular cells had COX2 levels that were similar to those of wild-type cells (Figure 6D). Altogether, these data showed that CLOCK-deficient renal tubular cells accumulate excess reactive oxygen species, causing the up-regulation of COX2.

Increased Expression of Cyclooxygenase 2 in CLOCKDeficient Mice after UUO and Celecoxib Treatment Attenuation of Renal Fibrosis in CLOCK-Deficient Mice

Based on the evidence that CLOCK deficiency increases TGF- $\beta$ levels, oxidative stress, and up-regulates COX2, we explored whether the selective inhibition of COX2 can ameliorate exacerbated renal fibrosis after UUO in CLOCKdeficient mice. First, we studied whether COX1 or COX2 showed circadian oscillation in kidneys. The COXI and COX2 transcripts showed no circadian oscillation in wildtype mice. However, in CLOCK-deficient mice, COX1 and COX2 transcripts showed paradoxic oscillation with higher levels than in wild-type mice (Figure 7A). Although COX1 protein levels in wild-type mice with and without UUO were similar, COX1 protein levels in CLOCK-deficient mice were increased (Figure 7B). COX2 protein levels were nearly absent in wild-type mice and were increased significantly in CLOCK UUO kidneys (Figure 7B). These results support the possibility that the inhibition of $\mathrm{COX} 2$, a downstream effector of TGF- $\beta$, is a potential therapeutic target of renal fibrosis that is caused by CLOCK deficiency. We then treated CLOCK-deficient mice with the oral selective COX2 inhibitor, celecoxib, after UUO and analyzed the severity of renal fibrosis. Picrosirius red staining showed that celecoxib effectively inhibited interstitial fibrosis in CLOCK-deficient mice (Figure 7, C and D). Consistent with the results of picrosirius staining, celecoxib treatment significantly reduced the $\alpha$-smooth muscle actin mRNA and protein levels in CLOCK-deficient kidneys after UUO (Figure 7, E and F). These results support the fact that the selective inhibition of COX2 effectively reduced the renal fibrosis that was caused by CLOCK deficiency after UUO.

\section{Discussion}

Our results provide evidence that tubulointerstitial fibrosis after UUO was controlled by the circadian gene Clock. After UUO, the circadian oscillatory amplitude increased as a protective mechanism. The CLOCK-deficient mice, which did not have this circadian protective mechanism, showed exacerbated fibrosis after UUO. The enhanced fibrotic responses were mediated by clock-controlled TGF- $\beta$ and its downstream target COX2. Moreover, the selective inhibition of COX2 reduced fibrosis after UUO in CLOCKdeficient mice. These observations provided a new signaling insight into the mechanisms of interstitial fibrosis after UUO and the pathogenesis of chronic kidney diseases.

The interaction between TGF- $\beta$ signaling and circadian rhythm is complex. Our data have shown that the control of TGF- $\beta$ expression by CLOCK-BMAL1 heterodimers is through TGF- $\beta$ promoter E-box. TGF- $\beta 2$ has been shown to inhibit the expression of PER1, PER2, NRID1, and DBP in neurons. ${ }^{39}$ Consistent with our data, in the rabbit aqueous humor, TGF- $\beta 2$ shows endogenous circadian rhythms. ${ }^{40}$ Activation of TGF- $\beta$ signaling resets the circadian clock. ${ }^{41}$ Moreover, an exploration of the publicly available circadian expression profiles database showed that TGF- $\beta 1$ is a clock-controlled gene. ${ }^{42,43}$ These results support the finding that TGF- $\beta$ signaling is an interacting molecular clock pathway.

The finding that CLOCK-deficient kidneys showed increased oxidative stress markers is consistent with previous studies. ${ }^{44}$ BMAL1-deficient fibroblasts showed an increased sensitivity to hydrogen peroxide and a disrupted regulation of reactive oxygen species homeostasis. ${ }^{45}$ CLOCK mutant mice also respond to low-dose irradiation with accelerating aging phenotypes. ${ }^{46}$ Indeed, the reactive oxygen species, when induced, have their own circadian rhythms. ${ }^{47}$ Our study and previous evidence has suggested that circadian disruption can result in deregulated oxidative stress, which is responsible for increasing fibrosis, accelerated aging ${ }^{48}$ and carcinogenesis. We also found that SOD1, an antioxidant enzyme, was decreased significantly in CLOCK-deficient mice with or without UUO surgery (Supplemental Figure S4A). Moreover, SOD1 mRNA levels 
had robust circadian oscillation (Supplemental Figure S4B). In CLOCK-deficient mice, the SOD1 mRNA levels lost circadian oscillation and were significantly lower than in wild-type mice (Supplemental Figure S4B). Wild-type and CLOCK-deficient mice showed no difference in SOD2 mRNA levels and no circadian oscillation. These findings suggest that decreased SOD1 may be responsible for the increased oxidative stress in CLOCK-deficient kidneys. ${ }^{49}$

The effects of selective COX2 inhibition in chronic kidney diseases are controversial. In elderly patients with impaired renal function, COX2 inhibition may reduce glomerular filtration rates. ${ }^{50}$ Selective inhibitors of COX2 can prevent the progression of glomerular sclerosis in mice and reduce tubulointerstitial injury after UUO and diabetes. ${ }^{51,52}$ These observations imply that the COX2 inhibitor can be effective only in certain contexts, such as enhanced TGF- $\beta$ signaling or deregulated oxidative stress. The significant effects of COX2 inhibition in our study imply that circadian disruption indeed enhances oxidative stress and increases inflammatory responses. The effectiveness of treatment with a COX2 inhibitor in CLOCK-deficient mice with UUO herein provided evidence that enhanced fibrosis in these mice was caused by an enhanced TGF- $\beta-$ COX axis. However, this treatment cannot be used to treat all other chronic kidney disease because circadian disruption is only one of the many mechanisms that underlie the development of chronic kidney disease.

Consistent with our results, PER2-deficient mice also showed markedly increased cholestatic liver injury and fibrosis. The expression of fibrosis-related genes such as $T n f$, $T g f b 1$, and Timpl also was increased in PER2-deficient mice. ${ }^{19}$ These data suggest that circadian rhythm is critical in TGF- $\beta$ signaling and fibrotic homeostasis. However, we have performed UUO in PER2 mutant mice but failed to observe different fibrotic responses or kidney changes between PER2 mutant mice and wild-type mice (C.Y. Wang and S.L. Lin, unpublished data). Different clock genes may have different peripheral clock functions or impacts on organ functions, such as angiogenesis, aging, or oncogenesis.

CLOCK-deficient mice have lower blood pressure than wild-type mice. ${ }^{53}$ Blood pressure plays an important role in renal fibrosis and the UUO model. ${ }^{54}$ High blood pressure causes interstitial fibrosis, proteinuria, and glomerulosclerosis. Blood pressure reduction reduces glomerularcapillary pressure, inhibits interstitial fibrosis, and prevents the development of chronic kidney diseases. ${ }^{55,56}$ In mice, blood pressure lowering with angiotensin-receptor antagonists attenuates renal interstitial fibrosis in a UUO model. ${ }^{57}$ Based on evidence from clinical studies of blood pressure and related mice experiments, we assume that CLOCKdeficient mice with reduced blood pressure would have less renal fibrosis. However, in our studies, CLOCK-deficient mice had increased renal fibrosis despite having lower blood pressure. CLOCK may have multiple physiological effects in mice, including on blood pressure and renal fibrosis.

In conclusion, this study established that the circadian gene $C L O C K$ mediates the oscillation of TGF- $\beta$ signaling and COX2 activation, which promote kidney interstitial fibrosis (Figure 8). Targeting the CLOCK-TGF- $\beta-$ COX axis with celecoxib has effective therapeutic effects on renal fibrosis in Clock knockout mice after UUO. These data imply that the circadian rhythm in the kidney is a potential therapeutic target in the treatment of chronic kidney disease.

This study had some limitations. First, significantly increased TGF- $\beta$ mRNA levels were observed in CLOCKdeficient mice. However, in CLOCK-deficient MEFs, TGF- $\beta$ mRNA levels were decreased. Because the TGF- $\beta$ promoter is controlled by the circadian heterodimer CLOCK-BMAL1, a lower TGF- $\beta$ mRNA level in CLOCKdeficient context is reasonably expected. This paradoxic difference between circadian-deficient cells and mice also was observed in Per2 mutant mice. ${ }^{58}$ The exact mechanisms that underlie this difference are not known and presumably involve the circadian regulation of RNA processing ${ }^{59}$ or the dependence on the accuracy of in vivo mRNA accumulation on circadian rhythm. Future studies must be performed to investigate these possibilities. Second, we have found that SOD1 expression showed a robust circadian oscillation. CLOCK-deficient mice lost the circadian rhythm of SOD1 expression and showed lower SOD1 levels. The lower SOD1 levels in CLOCK-deficient mice may have been responsible for the increased oxidative stress. However, a further study using Sodl knockout mice will be needed to determine the mechanism.

\section{Acknowledgments}

We thank Mei-Hsiu Lin, Hui-Chiu Chen, Yu-Jung Hu, and Hui-Ting Su for technical assistance and Ted Knoy for editorial assistance. CLOCK-deficient mice on a C57BL/6J background were a gift from Drs. Steven M. Reppert and David R. Weaver (University of Massachusetts Medical School, Worcester, MA).

\section{Supplemental Data}

Supplemental material for this article can be found at http://dx.doi.org/10.1016/j.ajpath.2015.08.003.

\section{References}

1. Froy O: Circadian rhythms, aging, and life span in mammals. Physiology (Bethesda) 2011, 26:225-235

2. Bass J: Circadian topology of metabolism. Nature 2012, 491:348-356

3. Bass J, Takahashi JS: Circadian integration of metabolism and energetics. Science 2010, 330:1349-1354

4. King DP, Takahashi JS: Molecular genetics of circadian rhythms in mammals. Annu Rev Neurosci 2000, 23:713-742

5. Mohawk JA, Green CB, Takahashi JS: Central and peripheral circadian clocks in mammals. Annu Rev Neurosci 2012, 35:445-462

6. Duong HA, Robles MS, Knutti D, Weitz CJ: A molecular mechanism for circadian clock negative feedback. Science 2011, 332:1436-1439

7. Green CB, Takahashi JS, Bass J: The meter of metabolism. Cell 2008, $134: 728-742$ 
8. Zhang EE, Kay SA: Clocks not winding down: unravelling circadian networks. Nat Rev Mol Cell Biol 2010, 11:764-776

9. Stow LR, Gumz ML: The circadian clock in the kidney. J Am Soc Nephrol 2011, 22:598-604

10. Ijaz S, Verbeek J, Seidler A, Lindbohm ML, Ojajarvi A, Orsini N, Costa G, Neuvonen K: Night-shift work and breast cancer-a systematic review and meta-analysis. Scand J Work Environ Health 2013, 39:431-447

11. Brown DL, Feskanich D, Sanchez BN, Rexrode KM, Schernhammer ES, Lisabeth LD: Rotating night shift work and the risk of ischemic stroke. Am J Epidemiol 2009, 169:1370-1377

12. Wang CY, Wen MS, Wang HW, Hsieh IC, Li Y, Liu PY, Lin FC, Liao JK: Increased vascular senescence and impaired endothelial progenitor cell function mediated by mutation of circadian gene Per2. Circulation 2008, 118:2166-2173

13. Canuto R, Garcez AS, Olinto MT: Metabolic syndrome and shift work: a systematic review. Sleep Med Rev 2013, 17:425-431

14. Firsov D, Bonny O: Circadian regulation of renal function. Kidney Int 2010, 78:640-645

15. Cugini P, Halberg F, Sothern RB, Centanni M, Salandi E, Scavo D: Sodium restriction amplifies and propranolol loading inhibits circadian rhythm of plasma renin-angiotensin and aldosterone. Chronobiologia 1985, 12:155-165

16. Olgaard K, Madsen S, Roosen J, Hammer M: Circadian rhythm of plasma aldosterone and plasma renin activity in steroid and nonsteroid treated kidney transplanted patients. Scand J Clin Lab Invest 1977, 37:431-437

17. Nikolaeva S, Pradervand S, Centeno G, Zavadova V, Tokonami N, Maillard M, Bonny O, Firsov D: The circadian clock modulates renal sodium handling. J Am Soc Nephrol 2012, 23:1019-1026

18. Tokonami N, Mordasini D, Pradervand S, Centeno G, Jouffe C, Maillard M, Bonny O, Gachon F, Gomez RA, Sequeira-Lopez ML, Firsov D: Local renal circadian clocks control fluid-electrolyte homeostasis and BP. J Am Soc Nephrol 2014, 25:1430-1439

19. Chen P, Kakan X, Wang S, Dong W, Jia A, Cai C, Zhang J: Deletion of clock gene Per2 exacerbates cholestatic liver injury and fibrosis in mice. Exp Toxicol Pathol 2013, 65:427-432

20. Tamm C, Pijuan Galito S, Anneren C: A comparative study of protocols for mouse embryonic stem cell culturing. PLoS One 2013, 8: e81156

21. Zimmerman DL, Zimpelmann J, Xiao F, Gutsol A, Touyz R, Burns KD: The effect of angiotensin-(1-7) in mouse unilateral ureteral obstruction. Am J Pathol 2015, 185:729-740

22. DeBruyne JP, Weaver DR, Reppert SM: Peripheral circadian oscillators require CLOCK. Curr Biol 2007, 17:R538-R539

23. Etchegaray JP, Yang X, DeBruyne JP, Peters AH, Weaver DR, Jenuwein T, Reppert SM: The polycomb group protein EZH2 is required for mammalian circadian clock function. J Biol Chem 2006, 281:21209-21215

24. Yoo SH, Yamazaki S, Lowrey PL, Shimomura K, Ko CH, Buhr ED, Siepka SM, Hong HK, Oh WJ, Yoo OJ, Menaker M, Takahashi JS: PERIOD2::LUCIFERASE real-time reporting of circadian dynamics reveals persistent circadian oscillations in mouse peripheral tissues. Proc Natl Acad Sci U S A 2004, 101:5339-5346

25. Liu J, Malkani G, Shi X, Meyer M, Cunningham-Runddles S, Ma X, Sun ZS: The circadian clock Period 2 gene regulates gamma interferon production of NK cells in host response to lipopolysaccharide-induced endotoxic shock. Infect Immun 2006, 74:4750-4756

26. Lamia KA, Papp SJ, Yu RT, Barish GD, Uhlenhaut NH, Jonker JW, Downes M, Evans RM: Cryptochromes mediate rhythmic repression of the glucocorticoid receptor. Nature 2011, 480:552-556

27. Zhou Q, Chung AC, Huang XR, Dong Y, Yu X, Lan HY: Identification of novel long noncoding RNAs associated with TGFbeta/Smad3-mediated renal inflammation and fibrosis by RNA sequencing. Am J Pathol 2014, 184:409-417

28. Wu CF, Chiang WC, Lai CF, Chang FC, Chen YT, Chou YH, $\mathrm{Wu} \mathrm{TH}$, Linn GR, Ling $\mathrm{H}$, Wu KD, Tsai TJ, Chen YM,
Duffield JS, Lin SL: Transforming growth factor beta-1 stimulates profibrotic epithelial signaling to activate pericyte-myofibroblast transition in obstructive kidney fibrosis. Am J Pathol 2013, 182:118-131

29. Lan HY: Diverse roles of TGF-beta/Smads in renal fibrosis and inflammation. Int J Biol Sci 2011, 7:1056-1067

30. Bottinger EP: TGF-beta in renal injury and disease. Semin Nephrol 2007, 27:309-320

31. Munoz E, Baler R: The circadian E-box: when perfect is not good enough. Chronobiol Int 2003, 20:371-388

32. Zeisberg M, Neilson EG: Mechanisms of tubulointerstitial fibrosis. J Am Soc Nephrol 2010, 21:1819-1834

33. Liang M, Woodard LE, Liang A, Luo J, Wilson MH, Mitch WE, Cheng J: Protective role of insulin-like growth factor-1 receptor in endothelial cells against unilateral ureteral obstruction-induced renal fibrosis. Am J Pathol 2015, 185:1234-1250

34. Patrignani P, Patrono C: Cyclooxygenase inhibitors: from pharmacology to clinical read-outs. Biochim Biophys Acta 2015, 1851: 422-432

35. Mederle K, Meurer M, Castrop H, Hocherl K: Inhibition of COX-1 attenuates the formation of thromboxane $\mathrm{A} 2$ and ameliorates the acute decrease in glomerular filtration rate in endotoxemic mice. Am J Physiol Renal Physiol 2015, 309:F332-F340

36. Rios A, Vargas-Robles H, Gamez-Mendez AM, Escalante B: Cyclooxygenase-2 and kidney failure. Prostaglandins Other Lipid Mediat 2012, 98:86-90

37. Fujihara CK, Antunes GR, Mattar AL, Andreoli N, Malheiros DM, Noronha IL, Zatz R: Cyclooxygenase-2 (COX-2) inhibition limits abnormal COX-2 expression and progressive injury in the remnant kidney. Kidney Int 2003, 64:2172-2181

38. Kitahara M, Eitner F, Ostendorf $T$, Kunter U, Janssen U, Westenfeld R, Matsui K, Kerjaschki D, Floege J: Selective cyclooxygenase-2 inhibition impairs glomerular capillary healing in experimental glomerulonephritis. J Am Soc Nephrol 2002, 13: $1261-1270$

39. Gast H, Gordic S, Petrzilka S, Lopez M, Muller A, Gietl A, Hock C, Birchler T, Fontana A: Transforming growth factor-beta inhibits the expression of clock genes. Ann N Y Acad Sci 2012, 1261:79-87

40. Liu JH: Circadian variations of transforming growth factor-beta2 and basic fibroblast growth factor in the rabbit aqueous humor. Curr Eye Res 2002, 24:75-80

41. Kon N, Hirota T, Kawamoto T, Kato Y, Tsubota T, Fukada Y: Activation of TGF-beta/activin signalling resets the circadian clock through rapid induction of Dec1 transcripts. Nat Cell Biol 2008, 10: $1463-1469$

42. Zhang R, Lahens NF, Ballance HI, Hughes ME, Hogenesch JB: A circadian gene expression atlas in mammals: implications for biology and medicine. Proc Natl Acad Sci U S A 2014, 111: $16219-16224$

43. Pizarro A, Hayer K, Lahens NF, Hogenesch JB: CircaDB: a database of mammalian circadian gene expression profiles. Nucleic Acids Res 2013, 41:D1009-D1013

44. Khapre RV, Kondratova AA, Susova O, Kondratov RV: Circadian clock protein BMAL1 regulates cellular senescence in vivo. Cell Cycle 2011, 10:4162-4169

45. Kondratov RV, Kondratova AA, Gorbacheva VY, Vykhovanets OV, Antoch MP: Early aging and age-related pathologies in mice deficient in BMAL1, the core component of the circadian clock. Genes Dev 2006, 20:1868-1873

46. Antoch MP, Gorbacheva VY, Vykhovanets O, Toshkov IA, Kondratov RV, Kondratova AA, Lee C, Nikitin AY: Disruption of the circadian clock due to the Clock mutation has discrete effects on aging and carcinogenesis. Cell Cycle 2008, 7:1197-1204

47. Kang TH, Reardon JT, Kemp M, Sancar A: Circadian oscillation of nucleotide excision repair in mammalian brain. Proc Natl Acad Sci U S A 2009, 106:2864-2867 
48. Chen WD, Wen MS, Shie SS, Lo YL, Wo HT, Wang CC, Hsieh IC, Lee TH, Wang CY: The circadian rhythm controls telomeres and telomerase activity. Biochem Biophys Res Commun 2014, 451:408-414

49. Temneanu RO, Motoc A, Zugun FE, Folescu R, Lupusoru CE, Zamfir CL: The relevance of circadian rhythms disruption on pulmonary SOD expression in rat. Rom J Morphol Embryol 2012, 53:789-793

50. Kenney WL: Nonsteroidal anti-inflammatory drugs and the kidney. Curr Sports Med Rep 2002, 1:125-126

51. Jiang F, Liu GS, Dusting GJ, Chan EC: NADPH oxidase-dependent redox signaling in TGF-beta-mediated fibrotic responses. Redox Biol 2014, 2:267-272

52. Kamata M, Hosono K, Fujita T, Kamata K, Majima M: Role of cyclooxygenase-2 in the development of interstitial fibrosis in kidneys following unilateral ureteral obstruction in mice. Biomed Pharmacother 2015, 70:174-180

53. Zuber AM, Centeno G, Pradervand S, Nikolaeva S, Maquelin L, Cardinaux L, Bonny O, Firsov D: Molecular clock is involved in predictive circadian adjustment of renal function. Proc Natl Acad Sci U S A 2009, 106:16523-16528

54. Palm F, Nordquist L: Renal oxidative stress, oxygenation, and hypertension. Am J Physiol Regul Integr Comp Physiol 2011, 301: R1229-R1241
55. Maschio G, Alberti D, Janin G, Locatelli F, Mann JF, Motolese M, Ponticelli C, Ritz E, Zucchelli P: Effect of the angiotensinconverting-enzyme inhibitor benazepril on the progression of chronic renal insufficiency. The Angiotensin-Converting-Enzyme Inhibition in Progressive Renal Insufficiency Study Group. N Engl J Med 1996, 334:939-945

56. Brenner BM, Cooper ME, de Zeeuw D, Keane WF, Mitch WE, Parving HH, Remuzzi G, Snapinn SM, Zhang Z, Shahinfar S; RENAAL Study Investigators: Effects of losartan on renal and cardiovascular outcomes in patients with type 2 diabetes and nephropathy. N Engl J Med 2001, 345:861-869

57. Ishidoya S, Morrissey J, McCracken R, Reyes A, Klahr S: Angiotensin II receptor antagonist ameliorates renal tubulointerstitial fibrosis caused by unilateral ureteral obstruction. Kidney Int 1995, 47 : $1285-1294$

58. Fu L, Pelicano H, Liu J, Huang P, Lee C: The circadian gene Period2 plays an important role in tumor suppression and DNA damage response in vivo. Cell 2002, 111:41-50

59. Fustin JM, Doi M, Yamaguchi Y, Hida H, Nishimura S, Yoshida M, Isagawa T, Morioka MS, Kakeya H, Manabe I, Okamura H: RNAmethylation-dependent RNA processing controls the speed of the circadian clock. Cell 2013, 155:793-806 